\title{
FORMATION OF PERSONAL CAPABILITIES IN THE UNDERGRADUATE TEACHER TRAINING
}

\begin{abstract}
In the paper the author deals with her experience with the realization of the interventiontraining program focused on the self-development related to the personality competencies in the professional preparation of teachers. It points out the efficiency of the experiential forms of education from the point of view of their personal corrective action. To verify the efficiency of the realized program, the Kirpatrick's evaluation model is applied here.
\end{abstract}

Keywords: Intervention program, personality abilities, Kirpatrick's evaluation model.

\section{Introduction}

The submitted paper focuses on the facts related to "autonomous being" [1] of a future teacher. Too little attention is paid to these facts in the current undergraduate training of teachers. We have to realize that self-concept and self-regulation significantly influence the teacher performance in practice. They compose a substantial part of their expertness and professionalism. Teacher agrees with the expert professional identity and becomes part of his personality [2]. The teacher should rely on personal paramaters of his/her teacher identity at least as much as he/ she relies on subject expertise and formal authority. The teacher cannot avoid demanding situations, problems and dilemmas, their solution cannot be trained before their real encounter. What the teacher can do is to process this experience in an individual way and try to keep his/her own integrity. In this context we have to remind the fact that the teacher has to know himself/herself if he/she wants to understand others. If a teacher wants to develop the positive self-assessment of children, heshe must also have sufficiently developed self-confidence and be a balanced and integrated personality.

The paper is focused on the self-development related to personal capabilities and competencies in the professional teacher training (Turek 2003, Kasacova, 2006, Kosova, 2006, Zelinova, 2006, Vasutova 2004, Russo, Boman, 2007, Dobbins 1996, Sollarova, 2001, Popelkova, 2000 and others). It accentuates interventiontraining program, experiential forms of education that lead to strenghtening personal competencies in the future teacher training.
Positive findings on interventiontraining program effectiveness for the support of optimal development or possible correcting of professional capabilities of students for their future teaching profession (level of social interaction, self-image, social and cognitive competence, creativity etc.) are stated by the following authors: Popelkova (2000); Popelkova, Zatkova (2004); Sollarova, Pohanka (2000); Sobolt, Saboltova (1993); Hamranova (2003) and others.

The objective of the realized program "Improvement of the personal capabilities of a future teacher for the needs of professional practice "was to support the optimal development or correct the professional capabilities of students for their future teaching profession. To develop personal capabilities:

To specifically focus on deepening the self-knowledge and self-understanding, to learn more about oneself, to experience the sense of one's own self-worth.

- To support resilience, and to optimize the personal characteristics/authenticity, acceptance, honesty, openness, empathy/.

- To contribute to increasing the perception of self-worth and improving the self-image.

\section{Research}

Research objectives

1. To determine the rate of efficiency of the realized program from the point of view of subjective evaluation of the program

\footnotetext{
* Katarina Mackova

Department of Pedagogical Studies, Faculty of Humanities, University of Zilina, Slovakia,

E-mail: katarina.mackova@fhv.uniza.sk
} 
by its participants in comparison with their initial analysis of expectations.

2. To determine the rate of influence of the group atmosphere (and its respective variables ) by the application of the interventiontraining program.

3. To evaluate the efficiency of the effects of the realized program from the point of view of development of the monitored intrapsychic personal variables.

4. To evaluate the opinions of the students about the realized program.

The characteristics of the research sample and the conditions of research implementation

We realized the empirical research using the pedagogical experiment. The influence of the created training program / independent variable / on a possible development of the observed personal characteristics /dependant variables/ was monitored. The interventiontraining program for improving the personal capabilities of the future teachers was realized at the Faculty of Humanities within 40 classes $/ 5$ blocks of sessions, 8 classes each /. An advantage of training blocks that lasted more days and were concentrated into short time period, in our case 2 weeks, is "the intensity of effects of individual training procedures, with the contribution of the group dynamics and the opportunity to work with group atmosphere (concerning strenghtening the experiential effects)“ [3] With short regular sessions with longer time duration (e.g. 2 classes daily within one semester) there is a disadvantage that it might be a problem for some participants to open up (in such a short time) and subsequently it might be impossible to work with the expressed behaviour and experience. However, an advantage with training designed in this way might be an opportunity to gradually involve the developing capabilities in the real social situations. After considering the above mentioned claims and with regard to the fact that the program concept was also based on the characteristics of the time duration of the encounter group sessions according to C. Rogers (1997) (most often 18 hours at the weekend or 40 hours in one week), we decided for the above mentioned time range and duration [4].

The research sample consisted of 28 students in the second year of a teaching field of study at the Faculty of Humanities of the University of Zilina (2 teaching specializations). The experimental group consisted of 14 students. The control group also consisted of 14 students in the second year of a teaching field of study at the Faculty of Humanities of the University of Zilina. "To develop the personal and social capabilities the optimal group consists of approximatelly 15 members"[3].

\section{Research methodology}

The pedagogical experiment was realized with the pretestposttest research design. In the experimental group the measurements were realized before and after the application of the interventiontraining program; in the control group without the training intervention in the same time range between the first and second measurement as in the experimental group.

Our selection and compilation of the set of research methods to monitor our program efficiency was based on the evaluation model of the Kirpatrick's model (1959), that is cited very often (e.g. Komarkova et al., 2001; Boye, Crosby, 1997; Eseryel, 2002; Kaufman, Keller, 1994; Holton, 1996, etc.). The Kirpatrick's model includes the evaluation of the training program and its effects on 4 levels. To evaluate the program in a complex way, we tried to adapt to this and select the methods that can serve for verification of the stated hypotheses and can be applied to the individual levels of the respective model.

The $1^{\text {st }}$ level is reactions: It is the most used method of the training evaluation. Besides the information about the general level of satisfaction, the fact whether the participants consider this program relevant for their personal growth and their work can be found significant. Possibly also the information about the type of applied methods can be considered useful. The awareness of this evaluation level can be a stimulus for the improvement of the training preparation and realization.

The $2^{\text {nd }}$ level is learning: The evaluation of the training on the level of learning means capturing the changes in the field of knowledge, attitudes and capabilities of the participants as the training results. Considering the nature of objectives it is important to capture the changes related to the attitudes of the participants. This concerns capturing the changes in the attitudes that are important from the point of view of transfer of new experience in the real situations (a positive attitude to the training program increases the probability that experience gained from it will be used in real situations). It is also important to capture the changes in the attitudes towards oneself, i.e. the changes in the self-assessment of the participants. For example how the selfconfidence of a person has been changed, how a person perceives some of his social competencies or some other aspects.

The $3^{\text {rd }}$ level is behaviour: The verification of efficiency on this level aims to find out whether after the training some positive changes in the behaviour of the participants occurred. If the training is a part of professional preparation, it is possible to determine after some time after the program completion whether the transfer from training into practice took place. If the confrontation with practice is not possible then it is possible to gain feedback whether the training was profitable for the real life situations of the participants. The opinions of the participants can be obtained via individual or group interviews, questionnaires or assessment scales.

The $4^{\text {th }}$ level is results: It predominantly concerns the results that are important for the organization functioning as a whole. It is really problematic to measure the final results of programs dealing with leading the people, commnication...Therefore on this level of research we should focus on indicators, possibly the indirect ones that influence achieving the results of the organization. One of the possible indicators is e.g. changes in 
the social climate/atmosphere (e.g. using the questionnaire or a structured interview).

a) To clarify the possible "Expectations within the program" we used the verbal statements of the participants at the beginning of this training program. The statements were spontaneous and of unlimited extent.

The humanistic psychology and its approach to the participants of the training sessions that are considered unique beings having the capacity of personal growth and competent enough to specify their own priority objectives within the program, served as an inspiration for the initial interview realization. The final evaluation had to consider the analysis of achievement of the objectives stated in this way. After the training completion it can be used as a base for the final reflection of participants.

b) The level of the overall self-assessment was determined with the help of Rosenberg's self-esteem scale -RSES (Rosenberg, 1965) (Kirpatrick's evaluation model: 2. Level).

c) The level of self-esteem was determined with the help of Questionnaire of Self-Awareness (Smékal, 2002). The questionnaire consisted of 32 questions. The agreement or disagreement with a statement is expressed on a 5 point scale. After the evaluation the result is characterized by 5 levels (very high, high, healthy, rather low and low self-esteem) (Kirpatrick's evaluation model: 2. Level).

d) To clarify the influence of application of the training program on the group atmosphere we used the Questionnaire of the diagnosis of the climate/atmosphere/ in the group [5]

The questionnaire monitored the four components of our experience: empathy, acceptance, appreciation of value and congruence. (Kirpatrick's evaluation model: 4. Level)

e) To complete the quantitative indicators and to clarify the questions we asked when stating our research objectives we used the analysis of the records of the observers. Before the start of each session we randomly chose one of the participants that was given the role of an observer. The observers took parts in the sessions in the role of independent assessors and did not interfere with the group events.

The observers were given these instructions before the start of each session:

- to monitor and record the verbal statements of students,

- to monitor and record the verbal statements of the tutor /towards the students/,

- to monitor and record the group atmosphere during the sessions,

- to monitor and record the level of expressions of acceptance of the students by the tutor,

- to monitor and record the level of expressions of rejection and negative evaluation by the tutor.

f) With the aim of determination of the possible benefits of the training program after its attendance for the participants of the experimental group we used a slightly modified questionnaire by Popelková [6]: Questionnaire of the subjective evaluation of the interventiontraining program (Kirpatrick's evaluation model: 3. Level).

g) To complete the quantitative data from the questionnaire methods, we decided to apply the feedback technique by the students after the training program realization. Feedback means providing the other person with information about the way other people perceive, understand and experience his/ her behaviour. The level and depth of feedback depend on the level of trust among the group members. The feedback information can take many forms. We were interested in the verbal form that enabled us to characterize the group events during the experiment from the point of view of experiencing them by the students and the overall evaluation of the training program /Kirpatrick's evaluation model: 1. level/.

h) The analysis and interpretation of the research results we used the method of a logical analysis and mathematical statistics. To determine the statistical significance of differences between the measurement results in the experimental and the controlgroup, as a function of application of the intervention/ training program to the observed personal variables, we used the Cochran - Cox test.

To determine the statistical significance of differences of the observed variables between measurement 1 and measurement 2 we used the paired $t$ - test [7].

\section{Analysis and interpretation of the research results}

Interpretation of the analysis of expectations within the program

In the beginning of the training program the participants were asked to provide us with verbal statements of their subjective expectations related to the intervention/training program they were supposed to attend afterwards. The statements were spontaneous and unlimited in their extent. In our experimental group we recorded 37 expressed expectations altogether. The analysis showed that the most frequent category of expectations was to gain capabilities for the future teaching practice, to improve one's communication skills, to get to know one's personality better and to increase self-esteem.

The free and accepting environment helps the participants consider themselves as personalities competent enough to set their own prority objectives within the respective program.

The mentioned expectations became a basis for stating the objectives of the process by the actual process realization and at the end they served as a basis for the final self-reflection of the participants related to the achievement of the objectives they had set.

Influence of the interventiontraining program on the level of the overall self-assessment and self-esteem of an individual

With the help of methods of the intervention/training program, by discovering new facts about oneself and other people 
Significance of differences of the rate of overall self-assessment (RSES) and self-esteem (DSV) between the experimental and control group in measurement 1

Table 1

\begin{tabular}{|l|l|l|l|}
\hline & EXPERIMENTAL GROUP & CONTROL GROUP & T-TEST \\
\hline Average RSES & 29.29 & 26.29 & 1.89 \\
\hline Average DSV & 52.36 & 59.79 & 1.33 \\
\hline
\end{tabular}

Significance of differences of the rate of overall self-assessment (RSES) and self-esteem (DSV) between the experimental and the control group in measurement 2

Table 2

\begin{tabular}{|l|l|l|l|}
\hline & EXPERIMENTAL GROUP & CONTROL GROUP & T-TEST \\
\hline Average RSES & 32.14 & 28.14 & $2.5470^{*}$ \\
\hline Average DSV & 45.43 & 59.79 & $-2.5180^{*}$ \\
\hline
\end{tabular}

we can contribute to a more realistic self-image and higher selfesteem of a person. By positive experience in the social group we contribute to the increased perception of one's self-worth and improving one's self-image [8].

The indicator of the rate of the overall self-assessment was the average of the sum of the points of all the group members on the Rosenberg's self esteem scale (RSES) /the higher the sum of points the higher the level of overall self-esteem/. The resulting level of self-esteem was the average of the sum of points gained in the Questionnaire of Self-Awareness (DSV)/the higher the sum of points, the lower the self-esteem level/. The average values served to determine the significance of differences between the groups as well as in the groups between the measurement no.1 and measurement no.2.

With the aim to determine the differences in the level of overall self-assessment (RSES) and self-esteem (DSV) between the experimental and control group, by the t- test (Cochran-Cox test) we observed the statistical significance of the differences in the results of the students in both groups. From data in Table 1 we found out that both groups (experimental and control group) were equal concerning the overall self-assessment (RSES) and self-esteem (DSV) in the beginning of the experiment. The results of the t- test also confirmed there were no statistically significant differences between the experimental and the control group.

From the data in Table 2, Fig. 1 we found out the averages of the rate of overall self-assessment (RSES) and self-esteem (DSV) at the end of the experiment in both groups. The obtained average points indicate a different level between the experimental and control group at the end of the experiment. On the basis of the statistical consideration we can subsequently state a statistically significant difference of averages of both variables in favour of the experimental group.

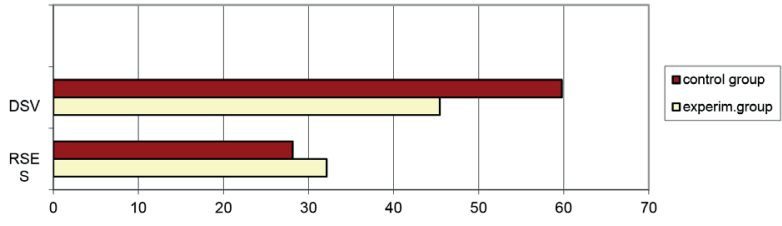

Fig. 1 The average values of the overall self-assessment (RSES) and self-esteem (DSV) coefficient in the experimental (ES) and control group (KS) in measurement 2

The comparison of measurement 1 and measurement 2 showed a significant increase of the level of overall self-assessment and self-esteem in the experimental group only (Table 3).

The average increase of values on the Rosenberg's self-esteem scale /RSES/ from the statistical point of view revealed a very significant $(\alpha=0.01)$ difference in averages between measurement 1 and measurement 2 in the experimental group, although in the control group in measuremement 2 the overall self-assessment of the respondents slightly increased compared to measurement 1. The average increase of values of self-esteem /DSV/ in the experimental group showed a shift from the level "rather low selfesteem" to the border of the level "healthy self-esteem" . From the statistical consideration we recorded a significant $(\alpha=0.05)$ positive increase of the level between the measurements in the beginning and at the end of the experiment.

Significance of differences of the rate of overall self-assessment (RSES) and self-esteem (DSV) within both groups (experimental-ES and control-KS groups) between measurement 1 and measurement 2

Table 3

\begin{tabular}{|l|c|c|c|c|}
\hline & Averageatthe beginning X1 & Averageatthe endX2 & DifferenceX2-X1 & T-test \\
\hline RSES- /ES/ & 29.29 & 32.14 & 2.86 & $3.09^{* *}$ \\
\hline RSES- /KS/ & 26.29 & 28.14 & 1.86 & 1.99 \\
\hline DSV-/ES/ & 52.36 & 45.43 & -6.93 & $2.154^{*}$ \\
\hline DSV-/KS/ & 59.79 & 59.79 & 0 & 0 \\
\hline
\end{tabular}


The statistical comparison between two measurements in the control group did not show any significant difference in the rate of the level of the overall self-assessment. The rate of the level of self-esteem in measurement 2 in the control group stayed on the same level when compared to measurement 1 . We did not record any statistically significant difference between the measurements.

The results indicate that the training program applied in the experimental group enabled the individual group members to experience positive personal experience that contributed to increased perception of their self worth.

According to Smekal [9] self-assessment scale has 2 ends: satisfaction and dissatisfaction with oneself. We also experience them as higher or lower self esteem. There is a positive linear relation between self-assessment and self-esteem which means that if we increase the overall self-assessment of a person, the self-esteem also increases. These parallels can be drawn in our research, too, where under the influence of the intervention program the values of both observed personal variables (RSES, DSV) increased significantly within the self-image of the students of our experimental group.

Concerning the overall self-assessment that is defined by Rosenberg as the overall relationship to oneself or the awareness of one's personal worth, it is also formed by the factor of selfassessment as a result of social comparison and the factor that represents the consideration of one's self worth, relatively independent on others. However, we cannot state that overall self-assessment is only a sum of these two components of selfassessment. It was found out that self-assessment is also formed by: experiencing positive and negative emotional states, specific view of oneself (concept of one's strengths and weaknesses) and the ways how the people construct various contents related to their own personality. It can be supposed that, during our experiment, we aimed to increase the part of self-assessment that is the result of social comparison / 1st factor/, because the purpose of the sessions was to provide positive feedback and appreciation of the performance of an individual by the group. According to Výrost, Slamenik [10] such self-assessment is more dependant on situational changes and is subject to frequent changes. Osecka, Blatny [11] found out in their research that the factors of the self-assessment scale are related to personal characteristics but this relation is not equally strong with both factors. The first factor shows closer relation to the personal characteristics. High self-assessment in both components is shown by those that are dominant, stable and extroverted. The factors also differ in the relation to the interpersonal dimension: hostility - affiliation. The hostile persons have higher global self-assessment (second factor) than affiliate persons. The high self-assessment based on comparison with others is not related to hostility.

If high self-assessment based on the factor of social comparison is not related to hostility then this claim supports our assertion about the possible increase of the rate of overall selfassessment in the experimental group via facilitating psycho-social atmosphere that was prevalent during the sessions (see analysis of the questionnaire of the group atmosphere and feedback from the participants of the sessions). It means that not only the specific partial self-assessments are important but also the overall emotional state and also the fact whether the person perceives the characteristics of his positive assessment as stable.

By the intervention of the training program we recorded a positive increase of particular variables of the group atmosphere I empathy, congruence, appreciation of value, acceptance/ in the perception of the participants. In all the observed variables except for the variable of empathy these results proved statistically significant compared to the control group.

When forming adequate self-assessment the overall emotional state plays an important role. The stated values help us understand one of the possible reasons of the positive change of overall selfassessment and self-esteem of the training sessions participants. Without accepting, open and emphatetic atmosphere in the group the experience leading to increasing the positive self-image would not be fulfilling enough.

From the recordings of the observers we found out that the atmosphere in the sessions was relaxed, active, there were many lively discussions, although some tension and expectations were evident in the beginning. The tutor communicated in a relaxed, friendly, lively and understandable way. According to the observers she was tolerant and emphatetic, praised the students for their activity and openness. The participants of the sessions spoke in a spontaneous and honest way expressed their current feelings and opinions.

Due to the necessity of completing the quantitative data, besides the method of observation and the initial interview by the verification of the of the program efficiency we applied the final interview "Feedback of the participants for the training tutor".

All the participants, as they confirmed, felt good in the sessions, some of them felt tired at long lasting activities. We realized a necessity to conduct the sessions in short lasting periods. The ability to better and objectively assess other people and to use the gained communication skills and experience in practice were among the expressed positives. Concerning the personal characteristics, some of them confirmed a shift in their self-perception and self-esteem. This fact was confirmed by the results of the Questionnaire of the overall program assessment, as well as by the the rate of the perceived overall self-assessment on the Rosenberg's scale (RSES) and self-esteem in the Questionnaire of Self-Awareness (DSV).

\section{Conclusion}

By the realization of the interventiontraining program, concerning the objectives of our research we consider fulfilling of expectations by the participants of the intervention/training program significantly high. They aspired to gain new capabilities 
for the future teaching practice, improve their communication skills as well as get to know their personality better and increase their self-esteem.

The results justify the application of the interventiontraining programs in the college training of the future teachers as an efficient method that supports the development of personal competencies and enhances the intrapersonal stability of students. The efficiency of the experiential forms of education and the educational environment especially from the point of view of their corrective personal action has also been proved here.

This paper looks at the transformation of teacher professional roles, emphasize personality powers in support of affective components of the "Self“ presents the project of improving undergraduate training in relation to personal identity parameters of teacher, teacher directed to the development of personal skills, as well as subsequent professional competence of future teachers.

In the Slovak education we are talking about the continuous teacher education where it is possible to intervene in this way conceived competence personality development programs. "The main objective is to increase professional competencies by creating a system of requirements and conditions for their professional development and career growth. The concept of professional development of pedagogical staff is published on the official web site of the Ministry of Education of the Slovak Republic“ [12, p. 52].

\section{References:}

[1] KOSOVA, B.: Professionalism Teacher - The Teacher as an Expert (in Slovak), Teacher Training and Actual Changes in Elementary Education, Jihoceska univerzita, Ceske Budejovice, 2005, 198 p., ISBN 80-7040-789-1

[2] MARES. J.: Educational Psychology (in Czech), Praha : Portal, 2013, 702 p., ISBN 978-80-262-0174-8

[3] KOMARKOVA, R., SLAMENIK, I., VYROST, J.: Applied Social Psychology-socio-psychological Training.(in Slovak), Praha : Grada, 2001, 224 p., ISBN 80-247-0180-4

[4] ROGERS, C.: Carl Rogers on Encounter Groups (in Slovak), Modra : Persona, 1997, 147 p., ISBN 80-967832-1-1

[5] ZELINA, M.: Humanization of Education (in Slovak), Bratislava : Psychodiagnostika spol. s r o., 1993, 83 p., ISBN 80-88714-00-1

[6] POPELKOVA, M.: Socio-psychological Training as an Element of Learning Environment (in Slovak), Non-traditional Forms of Learning Environment, Nitra : PF UKF. 2000. ISBN 80-8050-385-0

[7] TIRPAKOVA, A., MARKECHOVA, D., DANIEL, J.: Basics of Statistics and Methodology (in Slovak), Nitra : PF UKF, 1998, 128 p., ISBN 80-8050-226-9

[8] DOBES, M.: First Experience with Training Programs to Increase Positive Self-concept (in Slovak). Psychology and Patopsychology of Child, 34, 1999, 351-355. ISSN 0555-5574

[9] SMEKAL, V.: Invitation to the Psychology of Personality (in Czech), Brno : Barrister a Principal, 2002, 517 p., ISBN 80-85947-81-1

[10] VYROST, J, SLAMENIK, I.: Social Psychology (in Slovak), Praha : ISV, 1997. ISBN 80-85866-20-X

[11] KUFMAN, R., KELLER, J.: Levels of Evaluation: Beyond Kirkpatrick, Human Resource Development Quarterly, vol. 5, No. 4, 1994, (on-line), /cit. 2006-3-3/, Available at: http//www. Jpb.com/JBJournals/hrdq.html

[12] KUBALIKOVA, A.: Continual Education of Teachers - possibilities and New Challenges in the European Educational Space (in Slovak), Acta Humanica, No. 2a, 2012, p. 48-54. ISSN 1336-5126. 